\title{
Discurso de uma futura professora sobre sua identidade profissional ${ }^{1}$
}

Luciani Salcedo de Oliveira Malatér

Fundação Universidade Federal do Rio Grande (FURG)

RESUMO: Este artigo tem por objetivo investigar como uma futura professora de língua inglesa narra parte de sua constituição identitária, tendo como base os referenciais teóricos da Análise Crítica do Discurso (FAIRCLOUGH, 1989, 1992, 1995, 2003) e da Lingüística Sistêmico-Funcional (HALLIDAY, 1994, 2004). Com o intuito de pontuar as manutenções e/ou as mudanças discursivas ocorridas no período de coleta de dados - entre 2004 e 2007, a discussão dos dados está centrada em dois pontos principais: a) o tornar-se professora de língua estrangeira e b) a influência do Curso de Licenciatura nesse processo identitário. As conclusōes indicam que, ao narrar sobre sua constituição profissional docente, a participante da pesquisa revela que seu discurso é passível de mudança, tendo como condiçôes: a) tempo para trocar experiências com outros agentes sociais e b) oportunidade de historiar sua trajetória formativa enquanto professora, refletindo criticamente sobre sua identidade docente.

PALAVRAS-CHAVE: discurso; identidade docente; professora pré-serviço.

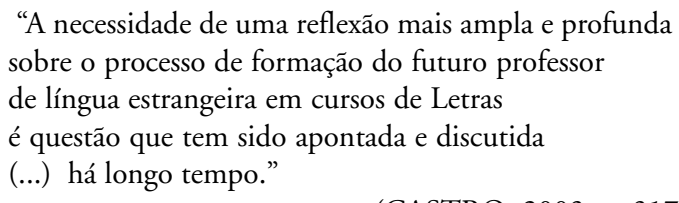

(CASTRO, 2003, p. 317).

\section{Introdução}

Em consonância com a citação de Castro, e com orientação da literatura da área, o objetivo deste trabalho é o de compartilhar representações discursivas de uma futura professora de Língua Inglesa sobre sua identidade profissional no ambiente de formação inicial. Este texto é originado do projeto de pesquisa

\footnotetext{
${ }^{1}$ Este trabalho integrou o Simpósio Paisagens líquidas: reflexōes sobre (per)cursos e (con)textos de formação docente (REICHMANN et al.), apresentado no I Congresso Internacional da ABRAPUI, UFMG, 2007.
} 
"A Construção Identitária de Futuros Professores de Língua Inglesa". ${ }^{2} \mathrm{O}$ objetivo principal do referido projeto é investigar como futuros professores ${ }^{3}$ de Língua Inglesa representam-se discursivamente, enquanto profissionais (CELANI, 2001), em textos por eles elaborados em dois diferentes momentos: ao cursarem o $2^{\circ}$. ano e o $4^{\circ}$. ano de um Curso de Letras Português/Inglês numa IFES gaúcha. Apesar de os dados terem sido produzidos por acadêmicos de uma turma da disciplina Língua Inglesa II, analiso aqui o discurso de apenas uma dessas futuras professoras, Simone. ${ }^{4}$ Tenho como foco investigar as manutenções ou mudanças discursivas sobre: a) o tornar-se professora de língua estrangeira e b) a influência do Curso de Licenciatura nesse processo identitário.

Nesta pesquisa, segue-se a definição de discurso enquanto "uma prática não só de representar o mundo, mas de significá-lo, constituindo-o e construindo-o em significados" (FAIRCLOUGH, 1992a, p. 64) [minha tradução]. Nessa prática, o discurso é visto como uma forma de co-participação social (MOITA LOPES, 2002), sendo então constituído no/pelo envolvimento de/com outros. Assim, os participantes discursivos agem no mundo por intermédio da linguagem, tendo a possibilidade de se tornarem conscientes de quem são ao construírem suas identidades sociais ao agir no mundo em circunstâncias culturais, históricas e institucionais particulares.

Para atingir os objetivos estabelecidos neste trabalho, a análise dos textos produzidos por Simone segue uma perspectiva interdisciplinar, fundamentandose não só em estudos da educação reflexiva de professores de língua (RICHARDS, 1998; CELANI, 2000; CRISTÓVÃO, 2002; DUARTE, 2002; CASTRO; ROMERO, 2006), mas também na análise crítica do discurso (ACD) (FAIRCLOUGH, 1989, 1992a, 1992b, 1993, 1995, 2003) e na lingüistica sistêmico-funcional (LSF) (HALLIDAY, 1991, 1993, 1994, 2004). A interface ACD/LSF tem sido considerada uma promissora possibilidade de pesquisa

\footnotetext{
${ }^{2}$ Contemplado com bolsa de Iniciação Científica em 2005/6 e 2006/7 (PROBIC/ FURG), tendo como bolsistas as acadêmicas Livia Pinto Ayter e Francine de Oliveira Gomes, respectivamente. $\mathrm{O}$ presente texto não possui co-autoria.

${ }^{3}$ Os termos futuro(s) professor(es) e professor(es) pré-serviço são utilizados para se referir a acadêmicos que freqüentam um Curso de Licenciatura, i.e. a "formação universitária inicial e profissional do professor" (VIEIRA-ABRAHÃO, 1999). No contexto da presente pesquisa, licenciandos do Curso de Letras Português/Inglês em uma IFES no extremo sul do Brasil.

${ }^{4}$ Nome escolhido pela própria participante da pesquisa, a fim de preservar sua real identidade. Sou muito agradecida a ela por compartilhar seu discurso conosco.
} 
(veja YOUNG; HARRISON, 2004, e YOUNG; FITZGERALD, 2006, por exemplo). Essa relação teórica possibilita estabelecer um melhor entendimento das complexidades envolvidas no processo social de tornar-se professor de Inglês como Língua Estrangeira (ILE), a partir da análise de textos produzidos por (futuros) professores de línguas (ver DELLAGNELO, 2003; REICHMANN, 2001).

Ao lançar um olhar mais crítico sobre a educação de professores préserviço, espera-se investigar a narrativa de suas experiências enquanto constituidora de identidade docente e, com isso, problematizar as representaçôes discursivas que eles têm dessas experiências. Portanto, sob o ponto de vista do futuro professor, este trabalho constitui-se num contexto de pesquisa sobre a complexa tarefa, atribuída a professores educadores, de educar professores de língua enquanto agentes críticos e autônomos.

$\mathrm{Na}$ próxima seção, alguns aspectos envolvidos no processo de construção discursiva docente são discutidos. Em seguida, a metodologia da pesquisa, descrevendo a participante, os procedimentos de coleta e de análise de dados, é apresentada. Logo depois, a análise e a discussão dos dados são detalhadas. Por fim, algumas implicações deste trabalho e os possíveis desdobramentos do mesmo são apontados.

\section{Uma possibilidade de olhar sobre o tornar-se professor}

Há uma recente tendência, no campo da educação de professores, ${ }^{5} \mathrm{em}$ se questionar como o exercício da docência é aprendido, e como a identidade dos professores é construída. Entre vários aspectos, que têm sido criticamente discutidos, está a concepção epistemológica positivista de ensino na qual muitos professores de línguas foram educados (ou melhor, "treinados"). Nessa concepção, os professores são vistos enquanto técnicos que aprendem e aplicam técnicas numa perspectiva de educação que os vê enquanto detentores do conhecimento (DEMO, 2002).

Com o intuito de se combater a perspectiva tecnicista de docência, tem havido um interesse crescente por se ouvir as vozes de professores para se tentar entender como eles tornam-se profissionais e porque decidem agir como o fazem. Podemos ver isso em trabalhos de Gimenez (1994), Telles (1996), Bailey e Nunan (1996), Richards (1998), Malatér (1998, 2005), Burns (1999), Libâneo (2001), Gimenez et al. (2003) e Romero (2004), por exemplo. Entretanto, considerando a existência de uma série de pesquisas que aponta a

${ }^{5}$ Optei pelo uso genérico do masculino, apesar de reconhecer orientaçōes contrárias. 
universidade como o foro formativo por excelência da docência (CELANI, 2001; NASCIMENTO DE PAULA, 2001), parece que ainda sabemos muito pouco sobre o impacto que os Cursos de Licenciatura têm sobre o desenvolvimento profissional de futuros professores. Ao salientar algumas das responsabilidades de cursos de formação pré-seviço, Celani (2000) afirma que o futuro professor teria, neste contexto formativo, suas crenças moldadas pelo discurso da "autoridade" em oposição à reflexão sobre a prática.

Neste estudo, há investigação do discurso - entendido enquanto o uso da linguagem como uma forma de prática social e manifestado na realização lingüística do texto (MEURER, 2005), de uma futura professora de ILE sobre sua identidade docente no Curso de Letras. Para tanto, a discussão e análise apóiam-se no uso de teorias lingüísticas e sócio-discursivas que apontam uma bidirecionalidade entre linguagem e sociedade (HEBERLE, 1997). Nessa perspectiva, a participante social é produzida e representada, e também produz e reproduz significados. Sendo assim, o discurso de Simone é considerado enquanto uma prática que, além de representar o mundo, dá significação a esse mundo. Em outras palavras, considera-se que o discurso de futuros professores constitui e constrói seus mundos no/pelo uso que fazem da língua/linguagem (FAIRCLOUGH, 1992a).

Nesta pesquisa, ao se considerar o Curso de Licenciatura como uma das marcantes influências constitutivas da identidade profissional de professores, acredita-se que o discurso de professores pré-serviço, centrado na construção do seu eu-professor, possa contribuir para o estabelecimento de uma melhor compreensão acerca dos papéis sociais a serem assumidos por futuros professores e por professores educadores.

Além de enfatizar a importância de se investigar diferentes visões e papéis sociais, a literatura considera ensinar um processo que requer uma constante reflexão crítica por parte daqueles inseridos em contextos educacionais. Segundo Liberali, Magalhães e Romero (2003), o conceito de "reflexão crítica" envolveria atores sociais num questionamento sobre suas ações e sobre as razóes pelas quais agem num dado contexto, levando-se em consideração aspectos sociais, políticos e culturais. Nessa perspectiva, reflexão é considerada uma "(...) possibilidade que se desenvolve do diálogo travado entre o ser humano e o seu mundo" (MATOS, 1998, p. 294) [grifo meu]. Nesse processo reflexivo, Magalhães (2002) argumenta que reflexão - "esse processo dialógico de autoconsciência das ações de linguagem (...)” (p. 50) - requer uma (re)discussão dos papéis tradicionalmente assumidos por professores, estudantes, pesquisadores, coordenadores. 
Com um movimento de valorização da formação e da profissionalização de professores, acentuado no início da década de 90, temos uma série de pesquisas que investigam a representação docente sobre diferentes dimensões (BURNS, 1992; NÓVOA, 1995; CELANI, 1997; ZEICHNER, 1998; VIEIRA-ABRAHÃO, 1999, entre outros).

O conceito de representação é entendido, neste texto, como sendo

(...) uma cadeia de significações construída nas constantes negociações entre os participantes das interações e as compreensōes, expectativas, intençōes, valores e crenças, 'verdades', referentes a teorias do mundo físico; a normas, valores e símbolos do mundo social e expectativas do agente sobre si mesmo enquanto sujeito em um contexto particular (isto é, significaçōes sobre seu saber, saber fazer e poder para agir). (MAGALHÃES, 2004, p. 66).

A proposta, aqui apresentada, focaliza as representações discursivas que a participante da pesquisa tem sobre seu saber, saber fazer e poder para agir, enquanto futura professora de línguas. Como salienta Halliday (1991, 1994, 2004), toda escolha lexicogramatical significa algo num dado contexto, sendo também reflexo/fruto desse contexto específico. Nessa perspectiva, Fairclough (1989) afirma que o texto materializa um ponto de vista, uma ideologia. Por esse motivo, analisa-se a textualização da participante da presente pesquisa com o objetivo de se explorar como o seu ser professor/fazer docente é influenciado pelo Curso de Licenciatura.

Fairclough (1992a) justifica a escolha pela integração entre LSF e ACD ao dizer que uma análise crítica do discurso estabelece uma 'ponte' entre análise lingüística de textos (como a proposta por Halliday) e teorias sociais da língua. O presente estudo propõe essa visão teórica interdisciplinar por também considerar discurso uma forma de prática social, sendo a representação do sujeito-professor construída numa relação bidirecional entre língua e sociedade.

A presente pesquisa, apoiando-se nesse paradigma teórico, justifica-se pelos seguintes fatos: a) busca aprofundar nossa compreensão acerca do desenvolvimento profissional do futuro professor de Língua Inglesa com o intuito de contribuir para sua busca de identidade crítico-reflexiva num Curso de Letras; b) pretende contribuir para um melhor entendimento do papel da linguagem na construção do conhecimento profissional e na prática reflexiva de futuros professores; e c) evidencia a representação discursiva enquanto algo complexo e caracterizado por incerteza, tensão, ambigüidade, fragmentação e conflito (MOITA LOPES, 2002; MAGALHĀES, 2004; CELANI, 2004).

Na próxima seção, abordo brevemente a metodologia da pesquisa. 


\section{Metodologia de Pesquisa}

A participante da pesquisa (Simone) era, em 2004, licencianda em um Curso de Letras Português/Inglês em uma instituição pública no extremo sul do Brasil. Nessa época, cursava o $2^{\circ}$. ano do Curso de Licenciatura e era aluna da disciplina Língua Inglesa II, ${ }^{6}$ na qual produziu texto, visual e escrito, detalhando seu discurso enquanto futura professora.

No início de 2007, já licenciada, Simone foi convidada a reescrever o texto que havia produzido em 2004. Além disso, aceitou participar de uma entrevista semi-estruturada na qual foi explicitamente perguntada se, entre os dois momentos de coleta de dados, teria havido alguma alteração ou permanência no seu narrar enquanto professora. O objetivo principal desse procedimento foi oportunizar à participante da pesquisa uma (re)textualização de sua identidade-docente-em-formação. A análise e discussão, aqui propostas, centram-se no texto transcrito da entrevista.

Compreende-se aqui o "papel das narrativas na construção das identidades sociais" (MOITA LOPES, 2002, p. 60). Portanto, as narrativas são situadas como discurso, ou seja, "como um tipo de organização discursiva" (MOITA LOPES, 2002, p. 60) no historiar de Simone sobre sua (re)leitura dos textos produzidos.

\section{Análise dos Dados}

Na presente pesquisa, considera-se que "não há significados à espera de significação; o significado é criado no uso da língua" (HALLIDAY, 1994, p. xii) [minha tradução]. Portanto, a língua é vista como um recurso para se construir significados, e esses residem nas escolhas sistêmicas feitas por participantes sociais num dado contexto (HALLIDAY; MATTHIESSEN, 2004, p. 23). Para a LSF, o fator central no "moldar de nossas experiências" está relacionado aos Processos selecionados (chamados, pela Gramática Tradicional, de verbos). Portanto, nossas experiências de vida são instanciadas nas escolhas lexicogramaticais que fazemos ao falar ou escrever. ${ }^{7}$ Sendo assim, o Sistema de Transitividade é especialmente enfocado neste texto, visto que, os participantes sociais e as noções de serlestar, dizer, sentir, agir, fazer e existir - centrais para a

\footnotetext{
${ }^{6}$ Ministrada pela autora.

${ }^{7}$ Numa perspectiva mais ampla, podemos incluir outras formas de expressão, e.g. pintar, cantar, moldar, dançar, desenhar, brincar.
} 
constituição da narrativa docente - são expressos nos Participantes, Processos e Circunstâncias utilizados pela participante da pesquisa.

Como apontado anteriormente, nesta pesquisa qualitativa (TELLES, 2002), os entendimentos sobre o processo de tornar-se professor de ILE (Inglês - Língua Estrangeira) são gerados a partir das representaçôes discursivas de uma recém-Licenciada em Letras. Passo, a seguir, à análise dos dados produzidos por Simone na entrevista realizada no dia $1^{\circ}$. de março de 2007 , com duração de 41 minutos, sendo que a mesma foi totalmente transcrita, sem que correçôes lingüísticas fossem inseridas.

Com relação a manutenções ou mudanças discursivas, foco da presente investigação, Simone diz que: “(...) quando eu comecei a analisar o outro desenho [coletado na primeira fase da pesquisa] ${ }^{8}$ eu vi que muita coisa, muitos itens ainda refletiam ainda hoje, e alguns itens eram absurdos...”. Interessante observar que a própria participante aceitou o desafio de (re)textualizar "como ela se vê, enquanto professora, depois de concluir o Curso de Licenciatura". Simone afirma que: "Eu não reescrevi o texto, porque assim ó o que eu utilizo, eu continuo o mesmo texto, eu só corrigi alguns pontos e adicionei esse ponto. Eu só fiz um texto que conecta (...). [O texto] continua o mesmo só que daí eu vou corrigindo que depois com a prática...”. Neste trecho, Simone salienta que, ao revisitar sua representação discursiva, percebe que houve alguma alteração no seu discurso. Esse fato fica evidenciado pelo uso da Circunstância "depois com a prática” [em sala de aula].

Com relação aos pontos específicos da investigação, observa-se:

\section{Discurso sobre o tornar-se professora de língua estrangeira}

Simone salienta a questão da professora "cheia de energia":

tu [enquanto professora] tem que dar tudo do teu conhecimento mas não tudo da tua energia, tu tem que saber dosar porque lá fora, existe a Simone que não é professora, a Simone que vive, que faz outras coisas (...). ${ }^{9}$

A participante da pesquisa aponta uma alteração no seu discurso com relação à "energia" utilizada para o desempenho da sua prática docente. Ela é consciente das suas obrigações, enquanto profissional, e traz consideração sobre

\footnotetext{
${ }^{8}$ Comentário (ou resgate de dados) da pesquisadora.

${ }^{9}$ Grifos da pesquisadora.
} 
sua vida pessoal, afirmando que esse ponto deve ser observado já que "muitas vezes a gente joga tudo pra profissão e acaba ficando só na profissão." Simone usa "tudo do teu conhecimento" como Meta ${ }^{10}$ (Goal, participante para o qual a ação é direcionada) do Processo Material ("dar"), nos termos hallidayanos. Interessante observar o uso do Verbo Relacional "ser", com polaridade negativa, em "a Simone que não é professora". Essa Simone também "vive" e "faz outras coisas", além da docência. A seleção dos Verbos Materiais "viver e fazer" denotam um Ator social que não desempenha um papel exclusivamente profissional.

Ao ser questionada se ainda se percebe enquanto "guia" de seus alunos, Simone afirma que sim, mas aponta ter mudado sua definição inicial a respeito:

Eu tinha mais a questão do guia e guiar para um caminho totalmente certo e aí agora a gente guia, mas também tem o outro que pensa do outro lado que é o aluno e ele vai pensar porque ele tem também o livre arbitrio de escolher.

Podemos observar que Simone não se vê mais enquanto uma professora que deve guiar seus alunos para "um caminho totalmente certo". Ela percebe que o aluno pensa, escolhe, valoriza, tenta seguir o caminho que julga adequado. Ao perceber seus alunos enquanto seres pensantes, Simone não põe sobre "seus ombros" toda responsabilidade pelas escolhas que eles venham a fazer. Sua tarefa é a de guiar, orientar, conduzir, mas seus alunos seriam os agentes de escolha de seus próprios rumos. Na perspectiva da LSF, Simone percebe-se enquanto Ator das ações a serem disponibilizadas aos alunos pela professora. Ela seria "a que guia”. Nesse contexto, os alunos são vistos enquanto Experienciadores (Sensor) das suas próprias escolhas. Apesar disso, Simone salienta a responsabilidade do professor ao dizer que: "(...) a gente tem que guiar muito, muito, muito porque tu que dá a direção da tua aula. Então tu é pago como se fosse um guia".

Nessa questão específica, fica claro que a futura professora foi influenciada pelo Curso de Licenciatura em seu (re)posicionamento. Simone afirma que

(...) porque de repente se a gente [professores] der tudo mastigado quando a gente chega aqui na faculdade eu lembro muito que a gente chegava, eu cheguei aqui e era tudo mastigado antes, eles davam tudo pronto. Aí tu chega aqui tu vê que tem que, pesquisar, tu tem que procurar, correr atrás...

\footnotetext{
${ }^{10}$ Ver http://www.fl.ul.pt/pessoais/cgouveia/artigos/TermosGSF.pdf ("Termos de Gramática Sistêmico-Funcional em Português”, lista de discussão gsfemportugues@ yahoogrupos.com.br - PUC-SP). Neste texto, utilizo os termos traduzidos por esse grupo.
} 
Nesse trecho, fica evidenciado um contraste entre Ensino Médio e Ensino Superior. No primeiro, "era tudo mastigado" [Atributo], ou seja, os conteúdos eram apresentados como prontos para o consumo, ao passo que, no Ensino Superior, o acadêmico tem que "pesquisar, procurar, correr atrás". O estudo passa, portanto, de uma atividade passiva na qual o estudante recebe "tudo mastigado" para uma situação na qual deve ele agir ativamente (tornar-se Ator). Essa observação, feita por Simone, lhe fez rever seu discurso a respeito do professor que atua como "guia" para um "caminho certo" (como observado anteriormente).

A participante da pesquisa diz que a postura docente precisa centrar-se na preparação do aluno para o questionamento, a pesquisa, a curiosidade, a busca e o pensamento crítico. Há, nesses trechos, evidências para se afirmar que Simone descrevia a ação docente como algo que era "certo", e passou a definir essa ação como algo "incerto". Os Processos Materiais envolvidos na prática docente alteram-se do "dar tudo mastigado" para o "orientar" seu aluno a questionar, pesquisar, buscar. Os alunos, enquanto atores sociais, nesse caso, passam a ser mais ativos e a assumir a responsabilidade de não esperarem por "algo pronto, algo a ser simplesmente consumido".

Ainda com relação a esta questão, Simone se vê como uma professora responsável pelo futuro de seus alunos, estabelecendo algumas relações entre a sala de aula e o "mundo lá fora". Ela afirma:

(...) fazer eles [alunos] construirem um conhecimento, buscarem por outros meios acredito que eles se tornam muito mais maduros e aí muito mais preparados para enfrentar outras questôes. Até porque dentro da LDB uma coisa que me chama muito a atenção é a questão de que nós devemos formar cidadãos. E como é que a gente forma cidadãos com um ensino mastigado?

Simone salienta, nesse trecho, a responsabilidade docente, apontada em documento oficial, de "formar cidadãos". Para que essa meta seja alcançada, o professor não pode simplesmente repassar conhecimento "mastigado", precisa, ao contrário, incentivar o aluno a construir conhecimento, buscar outros meios, amadurecer e preparar-se para desafios futuros. Nessa perspectiva, o ator professor deveria centrar suas ações na educação de alunos "mais maduros" e "mais preparados para enfrentar outras questôes" - na perspectiva hallidayana, esses Atributos dos discentes seriam conseqüência do envolvimento deles nas ações propostas por seus professores.

Outro ponto que sofreu alteração no discurso de Simone está relacionado ao uso de recursos didáticos em sala de aula: 
(...) É importante ter recursos, mas o recurso primordial é o aluno, aluno e professor. (...) E eu lembro que eu via assim muito a questão do recurso, que era importante. (...) Mas eu achava que eu incentivar a motivação era de repente trazer alguma coisa diferente pra sala de aula. (...) Essa questão que eu lembro que assim eu tinha muito ligada a mostrar coisas pro aluno pra ele ver. E hoje vejo que muitas vezes um simples sorriso pode motivar o aluno.

Observa-se, na fala de Simone, que há um deslocamento do recurso concreto/material ("mostrar coisas") para o afetivo/sentimental (dar/mostrar "um simples sorriso"). Apesar da escolha ter sido, nas duas situações, por Processos Materias, podemos perceber que a Meta foi alterada do concreto para o afetivo. Em consonância com essa concepção, Simone questiona também como seria trabalhar em uma escola com escassez de recursos materiais: "Então como é que eu vou trabalhar com isso então? Como é que eu vou fazer sem recurso? Se eu não me desligar dessa questão, eu não vou conseguir trabalhar numa escola de repente de periferia." Ela afirma que o recurso didático está relacionado ao afeto: "E hoje vejo que muitas vezes um simples sorriso pode motivar o aluno". Ainda com relação ao sentimento, ${ }^{11}$ Simone salienta que um contexto de trabalho, sem recursos materiais, não impede o desenvolvimento de sua tarefa profissional, devendo o professor "criar uma situação de aprendizagem". Mais uma vez, a participante da pesquisa, ao utilizar-se do Processo Material "criar", se vê enquanto um Ator que pode propiciar oportunidades de aprendizagem para os discentes. Nessa perspectiva, suas ações estariam direcionadas a seus alunos (Meta).

\section{Discurso sobre a influência do Curso de Licenciatura no processo identitário docente}

Uma questão marcante na fala da participante da pesquisa está relacionada ao questionamento que ela faz sobre a educação de professores no Curso de Licenciatura. Simone afirma que

O Curso de Letras pode formar técnicos na língua que saibam o uso da língua, mas ele não forma professores. Eu acho que professores vêm muito antes de um curso de graduação...

(...) os professores não têm tempo de ensinar a ser professor ou de passar essa experiência para nós. Eles têm que passar muito conteúdo.

\footnotetext{
${ }^{11}$ Questão também evidenciada em sua representação visual.
} 
(...) não tem como eles serem guias profissionais da gente, mas sim só dá uma pincelada, não dá tempo de ver tudo.

Simone afirma que, no Curso de Letras, formam-se "técnicos na língua", não professores. Além disso, salienta a falta de tempo enfrentada pelos professores educadores, devido à grande quantidade de conteúdo que devem ensinar. Assim, apenas "pincelam" algumas questões. É interessante observar o contraste existente entre: a) as açôes docentes da participante da pesquisa (Simone como Ator em orações com Processos Materiais), e b) as ações docentes que afirma serem adotadas por seus professores na Licenciatura (professores educadores como Atores em orações com Processos Materiais). Simone define-se como sendo aquela professora que "incentiva, motiva, dá [apoio, sorriso]", enquanto eles [professores educadores] "não passam experiências" para seus alunos e "dão pinceladas" [de conteúdo, experiência]. Porém, Simone afirma que o Curso de Letras é bastante exigente com relação à leitura e à disciplina de estudo, e que, depois da formatura, irá se dedicar aos tópicos que "realmente" são de seu interesse. Ela diz:

o curso pincelou e que eu tive vontade de fazer, mas de repente porque tinha aquela aula de literatura ou tinha que ler aquele livro ou tinha que estuda, ficou pra depois. Então agora parte o que, eu seguir o que realmente eu quero.

Com relação à formação docente, ela afirma

(...) mas, não sei, pra mim professores nascem professores não é que nem médicos ou engenheiros que a gente pode construir a técnica junto com eles... porque não tem como, nenhum professor te ensina como dar aula. (...) é algo que vem de ti, não é algo que alguém vai te dizer assim não tu tem que agir assim, técnicas existem (...) mas de que adianta trabalhar aquilo se tu não vê sentido naquilo?

eu acredito que tem muita pessoa que vem e que nunca pensou em ser professor entra num curso e realmente se descobre, mas eu acredito que é algo que tá lá dentro. Como se fosse inato.

Simone afirma que professores nascem [são] professores. Com o uso de Processo Relacional ("verbo de ligação" na Gramática Tradicional) com polaridade positiva, ela não dá nenhuma margem à dúvida: professores são [vêm ao mundo] professores. De certa maneira, o discurso da participante da pesquisa alinha-se à concepção de professor enquanto vocação, mas uma 
vocação que pode vir a ser influenciada pelo Curso de Licenciatura. Falando sobre sua vivência no Curso de Letras, Simone afirma que

Ele [o Curso] foi marcante pra mim muito, só que na questão assim de me mostrar muitas coisas, quebrar muitas concepçôes de ensino que eu tinha. Principalmente de ensino de línguas. O Inglês era só ensinar verbo. Só ensinar frase afirmativa, conjugação do 'to be'.(...) e quando eu entrei e quando eu me vi aqui eu me via muito dividida, fragmentada em conteúdo, e eu vejo que eu posso englobar tudo. Posso construir uma aula de inglês trabalhando uma literatura. (...) E aula de inglês é aula de gramática também. Era algo que eu tinha muito fragmentado e aí o curso me ajudo muito a ver que na verdade tá uma ligada com a outra.

Nesse fragmento, Simone diz que a Licenciatura "foi muito marcante", já que "quebrou" algumas de suas concepçôes, entre elas, a de que na aula de Inglês estuda-se somente o verbo "to be". Simone define-se como uma professora-em-construção "dividida e fragmentada”. Ao longo do Curso de Licenciatura, ela pôde "englobar" saberes e habilidades, estabelecendo, dessa maneira, pontes que podem auxiliar seus alunos na aprendizagem de línguas.

\section{Discussão dos Dados}

Ao analisar o discurso de Simone sobre si mesma como professora de línguas e sobre o Curso de Licenciatura, fica evidenciada a existência de alguns aspectos relevantes:

a) a necessidade de o professor dosar a energia empregada na atividade docente. Afinal, como a participante da pesquisa textualiza: "eu acredito que tem vida pessoal e vida profissional. Hoje eu tenho visto isso.". Observemos o uso da palavra "hoje", salientando uma mudança discursiva que foi influenciada pelas vivências que Simone teve enquanto aluna e também enquanto professora;

b) a percepção do professor enquanto aquele que "guia" seu aluno. Como Simone verbaliza: "só que com a perspectiva um pouquinho diferente do que eu tinha falado (...) só orienta (...)". Pelo contexto de pesquisa, é possível afirmar que o professor que "orienta" contrasta com aquele que "dá tudo mastigadinho". Portanto, para Simone, o professor não entregaria conhecimento pronto, mas incentivaria o aluno a pensar criticamente, buscar, posicionar-se; 
c) a mudança na concepção de "realidade". Influenciada por sua prática docente no estágio em Língua Inglesa, que lidou com histórias e contos infantis, Simone vê que realidade não é apenas o "concreto", mas acredita que, ao lidar com o imaginário e o fantástico, o professor possa "chegar ao mundo real" de seus alunos. Essa concepção, de acordo com ela, foi "construída com o tempo e com a prática". O discurso se desloca do fazer do professor para o fazer/sentir do aluno;

d) o discurso sobre o uso de "recursos" em sala de aula passou do concreto para o afetivo: "Hoje de repente tu faz uma conversa ou de repente só olha para ele [aluno] ou tu dizes assim 'muito bem' (...) eu tinha ["essa questão"] muito ligada a mostrar coisas pro aluno pra ele ver." No texto de Simone, novamente, podemos perceber que o professor passa a se preocupar com o sentir do seu aluno, quando antes o foco era no fazer do professor. As ações docentes, portanto, passam a ter $o$ discente como Meta (Goal, participante para o qual a ação é direcionada) do Processo Material, nos termos hallidayanos;

e) o planejamento das aulas é percebido como um guia para sua prática pedagógica. Essa percepção foi influenciada pela experiência que Simone teve enquanto aluna: "tem professores que vêm pra sala de aula sem planejar. Eles abriam o livro e diziam assim 'ah, vamos ver o tal texto hoje' e aí o professor não tinha lido, o professor não tinha se preparado. E eu acredito que esta questão do preparar, do buscar é muito importante antes de dar uma aula.";

f) a mudança na concepção de "amizade" entre professor-aluno. Influenciada por seu Curso de Licenciatura ("questão da amizade entre professor e aluno e é uma coisa que eu fui construindo dentro do curso"), Simone reafirma seu papel enquanto a professora-que-está-no-comando: "tu [professor] tem que também saber colocar essa distância do profissional que 'ó eu estou aqui para dar aula, não queiram vocês dar aula no meu lugar, não queiram vocês tomar conta da turma, quem guia a aula sou eu'." Ao mesmo tempo em que admite a possibilidade de ser amiga dos seus alunos, Simone também percebe a necessidade de definir claramente o papel docente e o discente;

g) a formação de professores no Curso de Letras depende da história de vida do futuro professor: "E eu acho que o curso de letras, ele forma, claro, professores" (comparar com próximo item). Apesar de ter afirmado que lidou com conteúdos/práticas de forma superficial ("pincelado"), o Curso foi "muito marcante" para que ela revisasse várias de suas concepções teóricas 
sobre o ensino de línguas: "Questão de conteúdos com certeza, a gente não entra aqui sabendo. A gente acha que português é só gramática, e depois vê que não é só isso. (...) é um curso que me ajudou muito a abstrair, a virar... tirar as coisas do concreto.";

h) a definição do ser professor é anterior ao Curso de Licenciatura. Simone crê na contribuição da formação inicial, mas não a vê como garantia de educação profissional, nem mesmo como a única influência. Ela afirma que: "Mas assim o ser professor tá antes de um curso de graduação." / "Eu acho que professores vêm muito antes de um curso de graduação...".

Ao sugerir que o ser professor antecede o Curso de Licenciatura, a participante da pesquisa, de certa maneira, questiona as possíveis contribuições desse contexto (MALATÉR, 2005). Ao relativizar o impacto do Curso de Licenciatura na formação de professores, o discurso de Simone alinha-se à afirmação da literatura especializada de que “(...) futuros professores são expostos à cultura de ensinar e aprender antes de decidirem por freqüentar um curso de educação profissional" (MALATÉR, 1998, p. 24) (ver, principalmente, LORTIE, 1975, "aprendizagem pela observação").

\section{Considerações Finais}

A análise da entrevista concedida pela participante da pesquisa possibilita a seguinte formulação com relação ao foco da pesquisa: Simone revela que seu discurso, enquanto professora, é passível de mudança. Isso se comprova pelo uso de escolhas lingüísticas como, por exemplo, "depois com a prática", "e hoje vejo que...", "era algo que eu tinha muito fragmentado...", "aí o curso me ajudou muito a ver que na verdade...", "eu tinha essa questão realmente muito de...", "porque hoje eu vejo que muitos professores...”. As oportunidades que teve para trocar experiências com seus professores educadores (durante o Curso de Licenciatura) e com seus alunos (em sua prática docente) foram fatores determinantes para que Simone percebesse mudanças significativas em seu discurso enquanto professora, trazendo, com mais frequiência, seus alunos para o centro de sua prática pedagógica.

Com relação a seu discurso sobre o Curso de Licenciatura, ela afirma que a principal influência está relacionada à revisão de paradigmas: "Ele [o Curso] foi marcante pra mim muito, só que na questão assim de me mostrar muitas coisas, quebrar muitas concepçóes de ensino que eu tinha. Principalmente de ensino de línguas." Interessante salientar que no intervalo de tempo entre as coletas de dados, Simone teve a chance de revisitar, maturar, dar (outro) sentido 
ao seu discurso tanto com relação à sua identidade docente, quanto à Licenciatura. Pode-se observar que houve reflexão crítica a respeito de suas vivências em sala de aula, agregando significações derivadas de sua prática como aluna e professora.

Nesta pesquisa, fica evidenciada a constituição identitária docente como uma experiência humana heterogênea, fazendo parte do "intricado mosaico de que somos feitos" (MOITA LOPES, 2002, p. 58). Levando-se em consideração a perspectiva emancipatória da ACD, que, como apontado por Meurer (2005, p. 82-83), busca: a) conscientizar os indivíduos a respeito da linguagem enquanto prática social; b) salientar que o discurso cria, reforça ou desafia formas de conhecimento ou crenças, relações sociais e identidades ou posições sociais; c) tornar visíveis as relações entre linguagem e outras práticas sociais, muitas vezes, não percebidas pelos indivíduos; d) investigar como a linguagem é usada para manter ou desafiar relações de poder presentes no mundo contemporâneo; e) considerar a interligação entre poder e ideologia presente nos textos que produzimos e nos que consumimos; f) apontar a localização histórica e a corrente contínua presentes em cada texto; é, sem dúvida, relevante desenvolver pesquisa sobre as textualizações que futuros professores produzem a respeito de sua identidade docente.

De acordo com a LSF (EGGINS, 1994), a vida social é permeada/ constituída/desenhada pelo modo como utilizamos a língua (linguagem), fazendo diferentes escolhas lexicogramaticais nos diversos contextos dos quais participamos. Nesse processo de significação que acontece através das escolhas que constantemente fazemos, o uso da língua é visto como funcional, semântico, contextual e semiótico. Foi nessa perspectiva que o uso da LSF na presente pesquisa possibilitou uma análise lingüística que permite uma descrição detalhada e sistemática dos padróes lingüísticos selecionados por Simone. Além disso, ao seguir essa teoria, foi possível associar-se à concepção teórica sobre língua como uma prática social, visão que vai ao encontro do que foi anteriormente postulado sobre educação de professores.

Como salientado na epígrafe deste artigo, espera-se que a presente pesquisa traga contribuiçõos para "uma reflexão mais ampla e profunda sobre o processo de formação do futuro professor" (CASTRO, 2003, p. 317), principalmente no que se refere ao desenvolvimento crítico de uma identidade do professor de ILE. Para tanto, sugiro que professores educadores e futuros professores estejam sempre engajados na constituição de professores reflexivos ou de intelectuais críticos e reflexivos, como sugere Pimenta (2002) (ver também SCHÖN, 1987). 
Como fica evidenciado neste texto, considera-se o ato de narrar fundamental para a constituição de uma identidade crítico-reflexiva de docentes. As narrativas de docentes-em-formação podem validar a concepção do professor enquanto um sujeito sócio-cultural em constante processo de reflexão crítica sobre sua atuação e constituído por suas experiências de sociabilidade e cultura.

\begin{abstract}
This paper aims at investigating how a prospective EFL teacher narrates part of her identity construction, following the theoretical support of Critical Discourse Analysis (FAIRCLOUGH, 1989, 1992, 1995, 2003) and Systemic Functional Linguistics (HALLIDAY, 1994, 2004). Aiming at contrasting her discourse in the data collected between in 2004 and 2007, the data discussion focuses on: a) the process of becoming a foreign language teacher and b) the influence of the Language Teacher Education Program (Curso de Letras/ Licenciatura) on this process. Conclusions indicate that, when narrating about her professional teaching identity, the research participant shows that her discourse may be changed when there are: a) time for exchanging experiences with other social agents, and b) opportunity for textualizing her discursive trajectory as a teacher, critically reflecting about her identity as a language teacher.
\end{abstract}

KEY-WORDS: discourse; identity; future language teacher.

\title{
Referências Bibliográficas
}

BAILEY, K. M.; NUNAN, D. (Ed.) Voices from the language classroom: qualitative research in second language education. Cambridge: Cambridge University Press, 1996. 466p.

BURNS, A. Teacher beliefs and their influence on classroom practice. Prospect, v. 7, n. 3, p. 56-66, 1992.

BURNS, A. Collaborative action research for English language teachers. Cambridge: Cambridge University Press, 1999. 259p.

CASTRO, S. T. R. A construção da competência docente do futuro professor de língua estrangeira: um estudo com alunos de inglês de um curso de Letras. In: BARBARA, L.; RAMOS, R. de C. G. (Org.). Reflexão e ação no ensinoaprendizagem de linguas: homenagem a Antonieta Celani. Campinas, SP: Mercado de Letras, 2003. p. 317-336.

CASTRO, S. T. R. de; ROMERO, T. R. de S. A linguagem na formação do educador. In: CASTRO, S. T. R. de; SILVA, E. R. da (Org.). Formação do profissional docente: contribuições de pesquisas em Lingüística Aplicada. TaubatéSP: Cabral Editora e Livraria Universitária, 2006. 335p. 
CELANI, M. A. A. Ensino de línguas estrangeiras: olhando para o futuro. In: CELANI, M.A.A. (Org.). Ensino de segunda lingua: redescobrindo as origens. São Paulo: EDUC, 1997. p. 147-161.

CELANI, M. A. A. You've snatched the carpet from under my feet: courses as contexts for change in in-service language teacher education. In: KOIKE, I. (Org.). Selected Papers from AILA'99. Tokyo: Waseda University Press, 2000. p. 242-258.

CELANI, M. A. A. Ensino de línguas estrangeiras: ocupação ou profissão? In: LEFFA, V. (Org.). O professor de línguas estrangeiras: construindo a profissão. Pelotas: EDUCAT, 2001. p. 21-40.

CELANI, M. A. A. Culturas de aprendizagem: uma abordagem fenomenológica. In: MAGALHĀES, M. C. C. (Org.). A formação do professor como um profissional crítico: linguagem e reflexão. Campinas: Mercado de Letras, 2004. p. 37-56.

CRISTÓVÃO, V. L. L. Uma experiência de reflexão e formação de professores. In: GIMENEZ, T. (Org.). Trajetórias na formação de professores de línguas. Londrina: Ed. UEL, 2002. p. 129-142.

DELLAGNELO, A. de C. K. Self-evaluative reports: a discursive investigation of teacher reflectivity. 2003. Tese (Doutorado em Letras/Inglês) - Universidade Federal de Santa Catarina, Florianópolis, 2003.

DEMO, P. Professor e seu direito de estudar. In: SHIGUNOV NETO, A.; MACIEL, L. S. B. (Org.). Reflexōes sobre a formação de professores. Campinas, SP: Papirus, 2002. p. 71-88.

DUARTE, V. C. Transformando Doras em Carmosinas: uma tentativa bem sucedida. In: CELANI, M.A.A. (Org.). Professores e formadores em mudança: relato de um processo de reflexão e transformação da prática docente. Campinas, SP: Mercado de Letras, 2002. p. 37-54.

EGGINS, S. An introduction to systemic functional linguistics. London: Pinter, 1994. 360p.

FAIRCLOUGH, N. Language and power. London: Longman, 1989. 259p.

FAIRCLOUGH, N. Discourse and social change. Cambridge: Polity Press, 1992a. $259 \mathrm{p}$.

FAIRCLOUGH, N. (Ed.). Critical language awareness. London: Longman, 1992b. 343p.

FAIRCLOUGH, N. Critical discourse analysis and the marketization of public discourse: the universities. Discourse and Society, v. 4, n. 2, p. 133-168, 1993.

FAIRCLOUGH, N. Critical discourse analysis: The critical study of language. London: Longman, 1995. 265p. 
FAIRCLOUGH, N. Analysing discourse: textual analysis for social research. London and New York: Routledge, 2003. 270p.

GIMENEZ, T. N. Learners becoming teachers: an exploratory study of beliefs held by prospective and practising EFL teachers in Brazil. Unpublished PhD thesis. UK: Lancaster University, 1994.

GIMENEZ, T. N. et al. Desenvolvimento de conhecimento prático pessoal: um estudo com estagiários. In: GIMENEZ, T. (Org.). Ensinando e aprendendo inglês na universidade: formação de professores em tempos de mudança. XVI Encontro Nacional de Professores Universitários de Língua Inglesa. Londrina: ABRAPUI, 2003. p. 191-201.

HALLIDAY, M. A. K. The notion of "context" in language education. In: LE, T.; McCAUSLAND, M. (Ed.). Language education: interaction and development. (Proceedings of the International Conference held in Ho Chi Minh City, Vietnam, 30 March - 1 April). 1991.p. 1-26.

HALLIDAY, M. A. K. New ways of meaning: a challenge to applied linguistics. In: Language in a changing world: Applied Linguistics Association of Australia. Occasional Paper Number 13. Deakin: Applied Linguistics Association of Australia. [Ninth World Congress of Applied Linguistics, Thessaloniki, Greece; April 1990], 1993, p. 1-41.

HALLIDAY, M. A. K. An introduction to functional grammar. $2^{\text {nd }}$ ed. London: Edward Arnold, 1994. 434p.

HALLIDAY, M.A.K.; MATTHIESSEN, C. An introduction to functional grammar. $3^{\text {rd }}$ ed. London: Edward Arnold, 2004. 689p.

HEBERLE, V. M. An investigation of textual and contextual parameters in editorials of women's magazines. Tese (Doutorado em Letras/Inglês). 1997. Universidade Federal de Santa Catarina, Florianópolis, 1997.

LIBÂNEO, J. C. Adeus professor, adeus professora?: novas exigências educacionais e profissão docente. 5. ed. São Paulo: Cortez. Coleção Questôes da Nossa Época; v. 67, 2001. 104p.

LIBERALI, F. C., MAGALHÃES, M. C.; ROMERO, T. R. de S. Autobiografia, diário e sessão reflexiva: atividades na formação crítico-reflexiva de professores. In: BARBARA, L.; RAMOS, R. de C. G. (Org.). Reflexão e ação no ensinoaprendizagem de linguas: homenagem a Antonieta Celani. Campinas, SP: Mercado de Letras, 2003. p. 131-165.

LORTIE, D. School teacher: a sociological study. Chicago: University of Chicago Press, 1975. 284p. 
MAGALHÃES, M. C. C. O professor de línguas como pesquisador de sua ação: a pesquisa colaborativa. In: GIMENEZ, T. (Org.). Trajetórias na formação de professores de lingua. Londrina: Ed. UEL, 2002. p. 39-58.

MAGALHÃES, M. C. C. A linguagem na formação de professores reflexivos e críticos. In: MAGALHÃES, M. C. C. (Org.). A formação do professor como um profissional crítico: linguagem e reflexão. Campinas: Mercado de Letras, 2004. p. 59-85.

MALATÉR, L. S. de O. A teacher's beliefs on language teaching and learning: a classroom study. 1998. Dissertação (Mestrado em Letras/Inglês) Universidade Federal de Santa Catarina, Florianópolis, 1998.

MALATÉR, L. S. de O. "What I am teaching, why I am teaching and also to whom I'm teaching": Discursive Construction of Prospective EFL Teachers. 2005. Tese (Doutorado em Letras/Inglês) - Universidade Federal de Santa Catarina, Florianópolis, 2005.

MATOS, J.C. Professor reflexivo? Apontamentos para o debate. In: GERALDI, C. M. G.; FIORENTINI, D.; PEREIRA, E. M. de A. (Org.). Cartografias do trabalho docente: professor(a)-pesquisador(a). Campinas, SP: Mercado de Letras: Associação de Leitura do Brasil - ALB, 1998. p. 277-306.

MEURER, José Luiz. Gêneros textuais na análise crítica de Fairclough. In: MEURER, J. L.; BONINI, A.; MOTTA-ROTH, D. (Org.). Gêneros: teorias, métodos, debates. São Paulo: Parábola, 2005. p. 81-106.

MOITA LOPES, L P. Identidades fragmentadas: a construção discursiva de raça, gênero e sexualidade em sala de aula. Campinas: Mercado de Letras, 2002. 232p. NASCIMENTO DE PAULA, M. Formação de professores na universidade: um espaço em construção. 2001. Dissertação (Mestrado) - Pontifícia Universidade Católica de São Paulo, 2001.

NÓVOA, A. (Coord.). Os professores e sua formação. Lisboa: Publicações Dom Quixote, 1995. 158p.

PIMENTA, S. G. Professor reflexivo: construindo uma crítica. In: PIMENTA, S. G.; GHEDIN, E. (Org.). Professor reflexivo no Brasil: gênese e crítica de um conceito. São Paulo: Cortez, 2002. p. 17-52.

REICHMANN, C. L. Reflection as social practice: an in-depth linguistic study of teacher discourse in a dialogue journal. 1998. $208 \mathrm{f}$. Tese (Doutorado em Letras/Inglês) - Universidade Federal de Santa Catarina, Florianópolis, 2001.

RICHARDS, J. C. Beyond training: perspectives on language teacher education. Cambridge: Cambridge University Press, 1998. 208p. 
ROMERO, T. Características lingüísticas do processo reflexivo. In: MGALHĀES, M. C. C. (Org.). A formação do professor como um profissional critico: linguagem e reflexão. Campinas: Mercado de Letras, 2004. p. 189-202.

SCHÖN, D. A. Educating the reflective practitioner. San Francisco: Josey-Bass, 1987. 376p.

TELLES, J. A. Being a language teacher: stories of critical reflection on language and pedagogy. Unpublished Ph.D. Thesis. University of Toronto, OISE Ontario Institute for Studies in Education, 1996.

TELLES, J. A. 'É pesquisa, é? Ah, não quero, não, bem!' Sobre pesquisa acadêmica e sua relação com a prática do professor de línguas. Linguagem \& Ensino, v. 5, n. 2, p. 91-116, 2002.

VIEIRA-ABRAHÃO, M. H. Tentativas de construção de uma prática renovada: a formação em serviço em questão. In: ALMEIDA FILHO, J.C.P. (Org.). $O$ professor de língua estrangeira em formação. Campinas, SP: Pontes, 1999. p. 29-50. YOUNG, L.; HARRISON, C. (Ed.). Systemic functional linguistics and critical discourse analysis. London: Continuum, 2004. 306 p.

YOUNG, L.; FITZGERALD, B. The power of language: how discourse influences society. London: Equinox, 2006. 325p.

ZEICHNER, K. M. Para além da divisão entre professor-pesquisador e pesquisador acadêmico. In: GERALDI, C.M.G.; FIORENTINI, D.; PEREIRA, E.M.A. (Org.). Cartografias do trabalho docente: professor(a)-pesquisador(a). Campinas, SP: Mercado de Letras: Associação de Leitura do Brasil - ALB, 1998. p. 207-236.

Recebido em outubro 2007. Aprovado em novembro 2007. 